BEduManageRs Journal

Borneo Educational Management and Research Journal, Vol.2, No.1, 2021

ISSN: 2747-0504

\title{
Manajemen Pusat Kegiatan Belajar Masyarakat
}

\author{
Jumrani L ${ }^{1}$, Susilo ${ }^{2}$, Hasbi Sjamsir ${ }^{3}$ \\ Universitas Mulawarman \\ e-mail: doktormp@fkip.unmul.ac.id, sjamsirhasbi@yahoo.com
}

\begin{abstract}
The purpose of this study is to obtain a complete and clear picture of PKBM Management in PKBM Salsabila, Pasir Belengkong District, which includes planning, organizing, implementing, monitoring, and evaluating.

This research uses a qualitative research approach with a case study design, the main informants are managers including the Chairperson, Secretary, treasurer, technical resource persons and tutors. Data collection is done by interview, observation, and study documentation

The results of research, management and data analysis that have been done by researchers by describing relevant theories about PKBM management are: (1). Planning of human resource tutors and staff development programs is carried out at the beginning of the new school year through workshops. (2). Organizing the tutor and employee human resource development program is done by forming a committee and division of tasks and responsibilities towards the implementation of the program. (3). Implementation of the tutor's human resource development program and has been going according to plan. (4). Supervision in the implementation of resource development programs is carried out in the field or indirectly through reports at weekly meetings. (5). Source of Funds are: (1) Operational operational assistance fund (BOP). (2) Parents' participation funds, called Monthly Mandatory Fees (IWB). (3) Kepititian funds originating from the participation of parents of students (6) The form of giving Rewards in the form of incentives from the foundation paid every month. (7). Parental support in implementing PKBM management (8). Implementation of management, in principle, does not exist, but there is a component in the management function in the development of human resources that has experienced a few constraints, namely the implementation time of activities and financing support in ideal program planning is not yet maximal.
\end{abstract}

Keywords: Management, Program Management, PKBM

\section{PENDAHULUAN}

Pemerataan akses pendidikan dewasa ini telah menjadi trend meraih Indeks Pembangunan Masyarakat (IPM), dimana memiliki 3 Indikator yang saling terkait, diantaranya Ekonomi, Pendidikan dan Kesehatan. Dari ke tiga faktor tersebut, pendidikan merupakan hal utama yang perlu dikembangkan, karena dengan proses pendidikan yang bermutu (Input) maka pengetahuan (output) akan bermutu pula. Hingga identik kepada kehidupan yang lebih baik, karena pengetahuan sebagai hasil dari pendidikan berkorelasi langsung dengan berbagai hal, baik kesehatan hingga kepada kehidupan ekonomi., khususnya bagi pendidikan dasar dan menengah. Pendidikan yang berkualitas dapat menghasilkan sumber daya manusia yang berkualitas dan produktif. Hal tersebut mendorong suatu Negara menjadi
Negara yang maju dengan pesat dalam perkembangan dan teknologinya.

Pembangunan nasional di bidang pendidikan adalah upaya untuk mencerdaskan kehidupan bangsa dan meningkatkan kualitas sumber daya manusia Indonesia dalam mewujudkan masyarakat yang maju, adil dan makmur serta dapat memungkinkan warganya untuk mengembangkan diri baik berkenaan dengan aspek jasmaniah maupun rohaniah (Prijono, 1996:58).

Peranan non formal (PNF) sangatlah penting dalam memberikan layanan akses pendidikan. PNF mampu membuka akses pendidikan bagi masyarakat yang membutuhkan dengan berbagai pendekatan serta strategi, terutama bagi orang dewasa yang pendidikannya tidak terlayani dikarenakan berbagai sebab. Bahkan PNF mampu memberikan kontribusinya 
BEduManageRs Journal

Borneo Educational Management and Research Journal, Vol.2, No.1, 2021

ISSN: 2747-0504

dalam membangun dan memberdayakan masyarakat baik pada dimensi personal, kelompok hingga komunitas yang telah terbentuk melalui sebuah sistem dan aturan, seperti kelompok petani, komunitas anak jalanan dan buruh pabrik. Seiring dengan kecenderungan perkembangan dan tuntutan masyarakat akhirnya pendidikan nonformal semakin berkembang.

Pendidikan nonformal sebagaimana tercantum dalam pasal 26 ayat ayat 4, diuraikan bahwa satuan pendidikan nonformal terdiri atas lembaga kursus, lembaga pelatihan, kelompok belajar, pusat kegiatan belajar masyarakat, majelis taklim dan satuan pendidikan yang sejenis. Satuan pendidikan nonformal yang saat ini berkembang pesat adalah Pusat Kegiatan Belajar Masyarakat (PKBM), yang pada awal rintisannya didirikan di tingkat kecamatan kemudian menyebar kesetiap desa atau kalurahan.Pada awal berdirinya PKBM merupakan tempat belajar bagi warga masyarakat di sekitar PKBM itu berada.

Jadi sangat jelas bahwa pusat kegiatan belajar masyarakat merupakan suatu wadah bagi kegiatan masyarakat untuk memberdayakan potensi dalam rangka menggerakkan pembangunan disegala bidang (Ekonomi, Sosial, Budaya). Apalagi pada masa saat ini perkembangan pembangunan sangat pesat yang membutuhkan tenaga kerja dengan ilmu, keterampilan, skill, serta pendidikan yang relevan. Secara implisit juga diakui masyarakat bahwa pendidikan nonformal sesungguhnya telah banyak membantu masyarakat, terutama dari kelompok masyarakat yang kurang beruntung untuk memperoleh pendidikan dan keterampilan yang bermanfaat sesuai dengan kebutuhan yang didukung oleh ijazah, sertifikat ataupun bentuk surat keterangan tamat pendidikan dan pelatihan lainnya yang disesuaikan dengan karakteristik program kebijakan pemerintah dan peraturan yang berlaku. Untuk berkualitas atau tidak nya suatu tempat pendidikan tentu juga disertai dengan peranan berbagai pihak yang terkait.

Dengan dasar inilah Penulis tertarik untuk mengetahui bagaimanakah pengelolaan PKBM Salsabila Kecamatan Pasir belengkong untuk dapat dijadikan rujukan baru tentang bentuk

pengembangan PKBM dimasa depana, terutama yang berkaitan perencanaan, pengorganisasian, pelaksanaan dan pengawasan pengembangan sumber daya manusianya sebagai kunci utama dalam menggerakkan lembaga PKBM tersebut serta sarana dan prasarana pendukung lainnya sehingga dapat menghasilkan output yang baik dan berkualitas.

\section{KAJIAN TEORI}

Menurut Ricky W. Griffin (2006) Mendifinisikan manajemen sebagai proses perencanaan, pengorgansasian, pengoordinasian dan pengawasan sumber daya untuk mencapai sasaran (goals) secara efektif dan efesien. Efektif berarti tujuan dicapai sesuai dengan perencanaan sedangkan efesien berarti tugas dilaksanakan secara benar, terorganisasi dan sesuai denan jadwal.

Definisi lain menurut Mary Parker Follet, menyatakan bahwa manajemen adalah seni menyelesaikan pekerjaan melalui orang lain artinya seseorang manajer bertugas mengatur dan mengarahkan orang lain untuk mencapai tujuan organisasi (Vocational Business, 2003:51).

Dari beberapa definisi tersebut dapat dipahami bahwa manajemen merupakan seni mengelola organisasi dengan memafaatkan tenaga dan pikiran orang lain yang dikerjakan dengan perencanaan yang matang, pengerorgnisasian dan pengawasan untuk mencapai hasil yang efektif dan efesien.

Manajemen Sumber Daya Manusia (MSDM) adalah bagian dari ilmu manajemen yang secara khusus mengelola tentang pengaturan peranan sumber daya manusia dalam kegiatan organisasi, dalam hal ini sekolah. Hal ini berkaitan dengan sumber daya manusia dalam proses pendidikan merupakan salah satu bagian yang sangat penting, baik itu guru maupun tenaga administratif. Oleh karena itu, sumber daya manusia dalam dunia pendidikan di sekolah khususnya memerlukan pengelolaan dan pengembangan yang baik sebagai upaya meningkatkan kinerjanya, agar mereka dapat memberikan kontribusi bagi pencapaian tujuan sesuai dengan yang diharapkan. Meningkatnya kinerja sumber daya manusia akan berdampak positif pada kinerja suatu lembaga dalam 
BEduManageRs Journal

Borneo Educational Management and Research Journal, Vol.2, No.1, 2021

ISSN: 2747-0504

menjalankan peranannya. Meningkatnya kinerja sumber daya manusia bukanlah sesuatu yang dapat terjadi dengan sendirinya, namun memerlukan pengelolaan yang terencana, sistematis dan terarah agar proses pencapaian tujuan organisasi dapat dilaksanakan secara efektif dan efisien. Hal ini sejalan dengan pengertian MSDM yang dikemukakan oleh Hasibuan dalam Ratama Arifin (Tersedia : http//fhinzzoepoe.wordpress.com) sebagai berikut : "Manajemen sumber daya manusia adalah ilmu dan seni mengatur hubungan dan peranan tenaga kerja agar efektif dan efisien membantu terwujudnya tujuan perusahaan, karyawan dan masyarakat." Dalam definisinya Hasibuan menekankan bahwa MSDM merupakan ilmu dan seni untuk mengatur sumber daya manusia secara efektif dan efisien dalam suatu organisasi guna mencapai tujuan yang telah ditentukan.

Perbandingan Model Michigan dan Model Harvard dalam MSDM (Dimodifikasi dari Masdar,Asmorowati \& Irianto, 2009; Gill, 1999) Aspek Model Michigan (Hard Model) Model Harvard (Soft Model) Fokus Kinerja individu untuk mencapai tujuan organisasi Manusia (SDM) sebagai aset organisasi Dasar Kontrol organisasi terhadap SDM Pengembangan manusia (human development) Konsentrasi Penyesuaian cara manajemen SDM dengan misi dan strategi organisasi Peningkatan kompetensi dan komitmen untuk daya saing organisasi Isi Siklus MSDM, manajemen strategis SDM Sistem MSDM, Outcome MSDM Komponen Struktur organisasi, misi dan strategi organisasi, MSDM yang terdiri dari seleksi, kinerja, penghargaan, imbalan dan pengembangan Pilihan kebijakan MSDM (sistem pekerjaan, imbalan, alur SDM, dan pengaruh karyawan), faktor situasional, faktor stakeholders, outcome SDM, dan konsekuensi jangka panjang Strategi - Penyelarasan antara SDM dengan strategi bisnis - SDM dianggap sebagai biaya - SDM dianggap sebagai faktor dalam produksi - SDM dianggap sebagai "human assets" - Mendorong komitmen dengan pelibatan, partisipasi dan komunikasi Sonnenfeld dan Maury Peiperl (dalam Greer, 1995) mengemukakan ada 4 tipologi strategi pengembangan mutu sumberdaya manusia, yaitu: 1) Tipe $c l u b$, 2) Tipe baseball team, 3) Tipe academy 4) Tipe fortress
Pendidikan non formal sudah ada sejak dulu dan menyatu di dalam kehidupan masyarakat lebih tua dari pada keberadaan pendidikan sekolah. Para Nabi dan Rasul yang melakukan perubahan mendasar terhadap kepercayaan, cara berfikir, sopan santun dan cara-cara hidup di dalam menikmati kehidupan dunia ini, berdasarkan sejarah, usaha atau gerakan yang dilakukan bergerak di dalam jalur pendidikan non formal sebelum lahirnya pendidikan sekolah. Gerakan atau dahwah nabi dan Rosul begitu besar porsinya pembinaan yang ditujukan pada orangorang dewasa dan pemuda. Para Nabi dan Rosul berurusan dengan pendidikan dan pembangunan masyarakat melalui pembinaan orang dewasa dan pemuda yang berlangsungnya diluar system persekolahan.

Tujuan PKBM adalah memberdayakan masyarakat untuk kemandirian, melalui program-program yang dilaksanakan di PKBM, agar dapat membentuk manusia yang memiliki pengetahuan, keterampilan, dan sikap, sedangkan fungsi PKBM sendiri adalah (Sihombing, 1999: 15): Sebagai wadah pembelajaran artinya tempat warga masyarakat dapat menimba ilmu dan memperoleh berbagai jenis keterampilan dan pengetahuan fungsional yang dapat didayagunakan secara cepat dan tepat dalam upaya perbaikan kualitas hidup dan kehidupannya, Sebagai tepat pusaran semua potensi masyarakat artinya PKBM sebagai tempat pertukaran berbagai potensi yang ada dan berkembang di masyarakat, sehingga menjadi suatu sinergi yang dinamis dalam upaya pemberdayaan masyarakat itu sendiri, Sebagai pusat dan sumber informasi artinya wahana masyarakat menanyakan berbagai informasi tentang berbagai jenis kegiatan pembelajaran dan keterampilan fungsional yang dibutuhkan masyarakat, Sebagai ajang tukar-menukar keterampilan dan pengalaman artinya tempat berbagai jenis keterampilan dan pengalaman yang dimiliki oleh masyarakat yang bersangkutan dengan prinsip saling belajar dan membelajarkan melalui diskusi mengenai permasalahan yang dihadapi.

Keefektifan Pengelolaan PKBM Menurut Mulyono (2011: 35) unsur-unsur penting dalam pengelolaan PKBM adalah: a) misi PKBM yang setia dengan pendidikan kesetaraan, b) struktur organisasi yang fungsional PKBM secara 
BEduManageRs Journal

Borneo Educational Management and Research Journal, Vol.2, No.1, 2021

ISSN: 2747-0504

proposional dan profesional, c) kemitraan dan pelayanan yang baik terhadap PKBM secara efektif dan terbuka untuk menjaga citra PKBM sebagai media pendidikan kemasyarakatan secara umum, e) pengelolaan dan suvervisi sumber daya manusia secara efektif, f) dinamika dalam menjalankan strategi pembelajaran untuk meningkatkan mutu PKBM, g) penguatan kurikulum praktis sesuai dengan disiplin PKBM yang serba praktis untuk menunjang peningkatan pengetahuan warga belajar dan masyarakat, h) pengelolaan sumber daya belajar secara efektif, i) Pengelolaan dan pemeliharaan fasilitas PKBM secara baik dan efektif, j) Sistem konsekuensi dan tanggung jawab yang teratur berdasarkan indikator pengelola.

\section{METODE PENELITIAN}

1. Metode dan Pendekatan

Penelitian ni menggunakan metode studi kasus yang bertujuan untuk menjelaskan dan menganalisis mengenai gambaran Manajemen PKBM Salsabila Pasir Belengkong dengan menggunakan pendekatan kualitatif. Pedekatan Kualitatif adalah suatu proses penelitian yang menghasilkan temuan yang diperoleh dari data-data yang dikumpulkan melalui tehnik observasi partisipasi, wawancara mendalam dan studi dokumentasi.

2. Instrumen dan Sumber Data

Instrumen dalam penelitian ini adalah peneliti sendiri sebagai key instrument, sedangkan yang menjadi informan atau sumber data adalah adalah Ketua PKBM, sebagai informasi kunci sedangkan Yayasan, Sekretaris PKBM, dan orang-orang yang terlibat langsung dalam pengelolaan PKBM di PKBM Salsabila Kecamatan Pasir Belengkong sebagai informan pendukung. Penentuan Informan (sumber data) dalam penelitian ini peulis menggunakan tehnik purposive sampling, dimaksudkan bahwa informan yang diambil tidak dimaksudkan untuk mewakili populasi, melainkan untuk mewakili informasi yang dibutuhkan dalam penelitian ini.

3. Proses Pengumpulan Data

Prosedur pengumpulan data dalam penelitian kualitatif melalui tahapan sebagai berikut (1) The stage of reflection (tahapan refleksi) (2) The Stage of planning (tahapan

perencanan) (3) The stage of entry (tahapan memasuki lapangan) (4) The Stage of productive Data Colection (tahapan Pengumpulan Data) (5) The stage of withdrawal (tahapan penarikan dini) (6) The stage of writing (tahapan penulisan hasil penelitian)

\section{HASIL DAN PEMBAHASAN 1. Perencanaan (planning)}

Dari hasil wawancara dari Ketua PKBM, Yayasan, Sekretaris dan Kepala TU PKBM Salsabila Pasir Belengkong dan didukung oleh hasil studi dokumentasi, dapat disimpulkan bahwa : (1) Pada awal tahun ajaran baru, Ketua PKBM menyusun perencanaan program pengembangan sumber daya manusia (tutor dan pegawai) (2) Strategi pengembangan sumber daya manusia yang direncanakan adalah pendidikan dan pelatihan (3) bentu kegiatan yang direncanakan adalah worshop sharing, KKT dan study visit ke PKBM-PKBM yang berkualitas serta kegiatan pembinaan sikap melalui tauziah.

\section{Pengorganisasian (organizing)}

Berdasarkan hasil wawancara dengan Ketua, Yayasan, Sekretaris, Kepala TU PKBM Salsabila dapat disimpulkan bahwa sebelum pelaksanaan pengembangan sumber daya manusia. PKBM Salsabila dibentuk kepanitiaan yang bertanggung jawab penuh terhadap kegiatan yang akan dilaksanakan,

\section{Pelaksanaan (actuating)}

Dari hasil wawancara dari Ketua PKBM, Yayasan, Sekretaris dan Kepala TU PKBM Salsabila Pasir Belengkong dan didukung oleh hasil studi dokumentasi, dapat disimpulkan bahwa bahwa program pengembangan sumber daya pendidikan dalam hal ini Tutor dan pegawai, dilakukan dengan strategi pendidikan dan pelatihan. terlaksana dengan baik,. Dalam pelaksanaan pengembangan sumber daya manusia yang kami rencanakan sebagian besar kami laksanakan sendiri dan sebagian juga kami bermitra dengan Forum PKBM dalam pengembangan pendidikan di PKBM kami, bahkan dengan lembaga-lembaga diluar Kalimantan Timur atau lembaga-lembaga yang berkompeten dalam pengembangan pendidikan, 
BEduManageRs Journal

Borneo Educational Management and Research Journal, Vol.2, No.1, 2021

ISSN: 2747-0504

sehingga pelaksanaan kegiatan pengembangan sumber daya manusia hanya dapat dilaksanakan pada hari minggu atau hari libur lainnya

\section{Pengawasan (controlling)}

Dari hasil wawancara dari Ketua PKBM, Yayasan, Sekretaris dan Kepala TU PKBM Salsabila Pasir Belengkong dan didukung oleh hasil studi dokumentasi, dapat disimpulkan bahwa bahwa pengawasan terhadap pelaksanaan program pengembangan sumber daya manusia di PKBM Salsabila Pasir Belengkong dilakukan secara langsung maupun secara tidak langsung. Pengawasan secara langsung dengan melihat langsung pada saat kegiatan dilaksanakan di lapangan, sedangkan pengawasan secara tidak langsung dilakukan dengan mempelajari hasil laporan dari panitia yang bertanggung jawab dalam pelaksanaan kegiatan

\section{Sumber Dana dan Penggunaannya}

Dari hasil wawancara dari Ketua PKBM, Yayasan, Sekretaris dan Kepala TU PKBM Salsabila Pasir Belengkong dan didukung oleh hasil studi dokumentasi, dapat disimpulkan bahwa sumber perdanaan dalam mendukung manajemen PKBM Salsabila Pasir Belengkong yaitu pertama. adalah dana partisipasi orang tua siswa yang kami sebut iuran wajib bulanan (IWB) yang kesemuanya ini dikelola PKBM. Dana ini kami gunakan untuk pembiayaan digunakan untuk menggaji kami setiap bulannya. Kedua.berasal dari bantuan operasional penyelenggaraan (BOP) nasional (pemerintah pusat) yang besarannya sudah ditentukan sesuai juknis, kemudian dana tersebut sepenuhnya kami yang mengelola dan kami juga yang mempertanggung jawabkan 1 . namun tidak dapat setiap tahunnya, Kemudian yang ketiga adalah dana partisipasi siswa baru yang biasa disebut uang bangunan, dana ini hanya ditarik sekali dan dikelola oleh yayasan. Yang keempat adalah dana kepanitiaan yang sumbernya dari partisipasi orang tua siswa misalnya ujian semester, kemah ilmiah, kunjungan pembelajaran dal alain-lain, dana ini murni dikelola oleh panitia pelaksana kegiatan untuk keperluan operasional.

\section{Dukungan Orang Tua Siswa}

Dari wawancara keempat kutipan hasil wawancara yaitu ketua, yayasan, sekretaris dan orang tua siswa dapat disimpukan bahwa orang tua siswa sangat mendukung penerapan manajemen PKBM Salsabila Pasir Belengkong, terutama yang berkaitan dengan pembangunan fisik PKBM dan pendanaan operasional PKBM maupun kegiatan intrakurikuler dan ekstrakurikuler siswa. Selain dukungan tersebut, orang tua ikut membimbing anaknya baik ketika anak berada di sekolah maupun disaat anak berada dirumah. Kondisi seperti ini tercipta karena adanya hubungan interpersonal antara lingkungan intexrnal PKBM Salsabila dengan orang tua siswa sangat kondusif.

\section{Kendala dan Solusi Penerapan Manajemen PKBM Salsabila}

Dari hasil wawancara dari ke empat informan tersebut, dua diantaranya memiliki kesamaan jawaban yaitu kepala TU dan sekretaris yang menyatakan bahwa pada prinsipnya tidak ada kendala yang berarti dalam menerapkan manajemen PKBM Salsabila Pasir Belengkong, khususnya pada program pengembangan sumber daya manusia, sedangkan ketua PKBM menyatakan bahwa kendala yang dialami dalam program pengembangan sumber daya

\section{PEMBAHASAN}

Pembahasan yang dilakukan ini fokus pada temuan dalam penelitian yang dikaitkan dengan teoritik yang relevan dengan fungsi pokok Manajemen di bidang pendidikan sebagai berikut :

\section{- Perencanaan (planning)}

Perencanaan adalah hal yang penting yang harus dilakukan untuk mewujudkan manajemen PKBM yang baik, karena perencanaan ini merupakan seluruh keputusan tentang tindakantindakan yang akan dilakukan pada masa yang akan datang tentu berawal dari perncanaan yang matang. Perencanaan yang baik dalam PKBM merupakan fungsi utama dalam mencapai tujuan pendidikan yang sesuai dengan target yang telah ditetapkan. Dengan demikian suatu program akan berantakan jika tidak terarah, perencanaan yang matang dan disusun dengan baik akan 
BEduManageRs Journal

Borneo Educational Management and Research Journal, Vol.2, No.1, 2021

ISSN: 2747-0504

memberi pengaruh terhadap ketercapaian tujuan 5. Sumber dana dan penggunaannya program.

\section{Pengorganisasian (organizing)}

Pengoorganisasian merupakan tindak lanjut setelah penyusunan perencanaan yang merupakan komponen kedua yang tidak bisa dipisahkan dari manajem PKBM yang baik. Pengorganisasian dilakukan untuk menghimpun sumber daya yang dimiliki lembaga dan memberdayakan secara efektif. Dalam pengorganisasian program pengembangan sumber daya manusia ketua PKBM melakukan pengorganisasian sebelum pelaksnaan pengembangan sumber daya manusia di PKBM melalui pembagian tugas dan tanggung jawab terhadap kegiatan yang akan dilaksankan.

\section{Pelaksanaan (actuating)}

Pelaksanaan (actuating) dalam manajemen di PKBM tidal lain merupakan upaya untuk menjadikan perencanaan menjadi kenyataan dengan melalui pengorganisasian yang baik dengan berbagai pengarah dan motifasi kepada panitia pelaksana kegiatan, agar dapat menjalankan beban kerja secara optimal sesuai dengan peran, tugas dan tanggung jawabnya

Pelaksanaan pengembangan sumber daya manusia di PKBM telah terlaksana dengan baik meskipun apa yang direncanakan tidak semua terealisasi semua dalam pelaksanaan pengembangan sumber daya manusia sebagian besar dilaksanakn sendiri dan sebagian juga bekerjasama denga Forum PKBM Kabupaten Paser maupun Provinsi Kalimantan Timur.

\section{Pengawasan (Controling)}

Pengawasan atau controlling merupakan fungsi manajemn yang sangat penting dalam pelaksanaan program di PKBM, karena semua fungsi terdahulu baik perencanaan, pengorganisasian

dan pelaksanaan tidak akan efektif tanpa disertasi fungsi pengawasan. Setiap pelaksanaan program baik rekrutmen maupun pengembangan program, ketua PKBM melakukan pengawasan baik secara langsung maupun secara tidak langsung.

Keuangan dan pembiayaan merupakan salah satu sumber daya yang secara langsung menunjang efektifitas dan efesinsi pengelolaaan pendidikan. Dalam penyelenggaraan pendidikan keuangan dan pembiayaan merupakan potensi yang sangat menentukan dalam merupakan bagian yang tak terpisahkan dalam kajian manajemen . Komponen keuangan dan pembiayaan pada suatu PKBM merupakan komponen penting yang menentukan terlaksanaya kegiatan belajar mengajar di PKBM bersama komponen lainnya. 1) Penggunaan dana Bantuan Operasional Penyelenggaraan (BOP) di PKBM Salsabila Paser Belengkong berdasarkan Petunjuk Teknis dari Direktorat Pembinaan PAUD dan Dikmas. 2). Penggunaan dana partisipasi orang tua siswa yang dikelola oleh yayasan, sekolah diwajibkan membuat proposal kegiatan yang akan dilakukan dan dilengkapi dengan kebutuhan dana, kemudian diusulkan ke yayasan, selanjutnya dana yang disetujui oleh yayasan dapat digunakan oleh sekolah sesuai kegiatan yang telah diprogramkan, kemudian hasil kegiatan dilaporkannya ke yayasan.

\section{Dukungan Orang Tua Siswa}

Pendidikan merupakan hal terbesar yang selalu diutamakan oleh para orang tua. Saat ini masyarakat semakin menyadari pentingnya memberikan pendidikan yang terbaik kepada anak-anak mereka sejak dini. Untuk itu orang tua memegang peranan yang sangat penting dalam membimbing dan mendampingi anak dalam kehidupan keseharian anak. Sudah merupakan kewajiban para orang tua untuk menciptakan lingkungan yang kondusif sehingga dapat memancing keluar potensi anak, kecerdasan dan rasa percaya diri.

\section{Kendala dan Solusi Dalam Penerapan Manajemen PKBM SALSABILA}

Penerapan manajemen sumber daya manusia di PKBM Salsabila yang meliputi prencenaan (planning) dan pengorganisasian (organizing), pelaksanaan (actuating) dan pengawasan (controlling) baik pada program pengembangan sumber daya manusia maupun pendanaan dan pemberian imbalan tutor dan pegawai pada prinsipnya tidak ada kendala yang berarti, karena di PKBM Salsabila menjunjung tinggi 
BEduManageRs Journal

Borneo Educational Management and Research Journal, Vol.2, No.1, 2021

ISSN: 2747-0504

kerjasama dan kebersamaan dan diperkuat oleh dukungan dari yayasan yang sangat baik.

\section{KESIMPULAN}

Hasil penelitian menunjukkan bahwa : (1). Perencanaan program pengembangan sumber daya manusia tutor dan pegawai di PKBM Salsabila Paser Belengkong dilakukan pada awal tahun ajaran baru melalui workshop oleh ketua PKBM, dan tutor. Strategi pengembangan tutor dan pegawai dilakukan dengan menggunakan pendekatan "make approach" yaitu: pendidikan dan pelatihan. (2) Pengorganisasian dalam program pengembangan sumber daya manusia tutor dan pegawai di PKBM Salsabila Paser Belengkong dilakukan dengan membentuk kepanitian dan pembagian tugas dan tanggungjawab terhadap pelaksanaan program. (3). Pelaksanaan program pengembangan sumber daya manusia tutor dan pegawai di PKBM Salsabila Kecamatan Paser Belengkong. Telah berjalan sesuai dengan rencana, karena adanya dukungan pengorganisasian yang baik dalam melakukan fungsi dan tanggungjawabnya sesuai dengan tugas dalam program. (4). Pengawasan dalam pelaksanaan program pengembangan sumber daya manusia di PKBM Salsabila Paser Belengkong dilakukan oleh unsur PKBM Salsabila bersama dengan dengan yayasan secara langsung di lapangan maupun secara tidak langsung melalui laporan pada pertemuan mingguan. (5). Sumber Dana dan Penggunaan Dana PKBM Salsabila Paser Belengkong adalah: (a) Sumber Dana PKBM Salsabila berasal dari : (1) Dana bantuan operasional penyelenggaraan (BOP). (2) Dana partisipasi orang tua siswa yang disebut Iuran Wajib Bulanan (IWB). (3) Dana kepanitian yang sumbernya dari partisipasi orang tua siswa untuk menunjang kelancaran pelaksanaan kegiatan. (b). Penggunaan dana di PKBM Salsabila Paser Belengkong dibagi menjadi dua berdasarkan sumber pendanaannya yaitu: (1) Bantuan Operasional penyelenggaraan, (2) Penggunaan dana bantuan orang tua. (6) Bentuk pemberian Imbalan berupa insentif dari yayasan yang dibayarkan setiap bulannya. Dari hasil wawancara dari Ketua PKBM, Yayasan, Sekretaris dan Kepala TU PKBM Salsabila Pasir Belengkong dan didukung oleh hasil studi dokumentasi, dapat disimpulkan bahwa (7).

Dukungan orang tua dalam penerapan manajemen PKBM Salsabila Paser Belengkong meliputi: (1) Pendanaan dalam pembangunan fisiki (sarana dan prasarana PKBM) dan non fisik (operasional sekolah, kegiatan intrakurikuler dan ekstrakurikuler siswa). (2) Pembimbingan dan pendampingan anak di lingkungn PKBM maupun di rumah. Oleh karena itu kerja sama supaya bisa seiring seirama dalam menggali potensi, kecerdasan dan rasa percaya diri anak. (8). Penerapan manajemen PKBM Salsabila, pada prinsipnya tidak ada kendala yang mengganggu jalannya program, namun ada komponen dalam fungsi manajemen dalam pengembangan sumber daya manusia yang sedikit mengalami kendala yaitu waktu pelaksaanaan kegiatan dan dukungan pembiyaan dalam perencanaan program yang ideal belum maksimal.

\section{DAFTAR PUSTAKA}

Alwi S, 2001. Manajemen Sumberdaya Manusia, Strategi Keunggulan Kompetitif. Edisi. Yogyakarta;BPFEY Yogykarta

Amin S. Zakariadan Sudarto, 2009, Seminar Nasional V Sumber Daya Manusia

Andrew J. Dubrin, 1990. Essentials of Manajemen West Chicago: SounthWestern Publising Co

Ashok Som, 2008. Innovative human resource management and corporate performance in the context of economic liberalization in india. The Internasional Journal of Human Resource Management, Vol. 19, No. 7, hal 1278-1297

Bungin, M. Burhan. 2007. Penelitian Kualitatif: Komunikasi, Ekonomi, Kebijakan Publik dan Ilmu Sosial Lainnya. Jakarta: Kencana Prenada Media Group

Cahyono, Bambang Tri, 1996. Manajemen Sumber Daya Manusia, Jakarta, Badan Penerbit lpwi, Jakarta

Creswell, J.W. 1998. Qualitatif Inquiryand Research Design. Sage Publication, Inc: California. 
BEduManageRs Journal

Borneo Educational Management and Research Journal, Vol.2, No.1, 2021

ISSN: 2747-0504

Danim, Sudarwan. 2008. Visi Baru Manajemen Sekolah; dari unit birokrasi kelembaga akademik, Bumi Aksara, Jakarta.

Deddy Mulyana, 2002. Metodologi Penelitian Kualitatif, PT. Remaja Rosda Karya, Bandung

Donni . J.P, 2018. Manajemen Pengembangan SumberDaya Manusia. Alfabeta, Bandung

Dessler, Gary, 2000. HumanResours Management, Internatinal Edition, 8 th Ed. Prentice Hall. Inc, Upper Saddie River, Nem Jersey

Famholtz E..G. 1996. Effective Management Control: Theory and Practice.Published by Kluwer Academic Publishers

Frend C. Lunenbung, 2012. Human Resource Planning International Journal of management practice in Morocco, Journal European Management Vol. 33, hal. 143156

Gomes Faustino Cordoso, 2003. Manajemen SumberDaya Manusia, Yogyakarta, Andi Offset.

Handari Nawawi dkk, 2003. Manajemen Sumberdaya Manusia untuk bisnis Kompetatif, Gajahmada University Press, Yogyakarta

Handoko Hani, 2003 Manajemen. Edisi 2. Yogyakarta

Hasibuan. Melayu Hasbi S.P., 2007, Manajemen Sumberdaya Manusia, PT. Bumi Aksara, Jakarta.

Hasibuan, Lias. 2004. Melejitkan Mutu Pendidikan; Refleksi, Relevansi dan Rekonstruksi Kurikulum. (Jambi:SAPAP roject).

Inu Kencana Syafiie,2018, Ilmu Manajemen, Pustaka Reka cipta, Bandung

Miles, Maththew B dan A. Michael Huberman, 1992. Analisi Data Kualitatif, Buku Sumber Tentang Metode-metode Baru, Universitas Indinesia - Preaa, Jakarta.

Moelong, Laxy J. 2004. Metodologi Penelitian Kualitatif, PT. Remaja Rosdakarya, Bandung

Moelong, Lexy J. 2007. Metodologi Penelitian Kualitatif, PT. Remaja Rosdakarya, Bandung.

Muhmidayeli, 2014. Teori-teori Pengembangan Sumberdaya Manusia dalam Pendidikan, PT Refika Aditama, Bandug.

Notoatmojodjo, Soekidjo, 2003, Pengembanagn sumberdaya Manusia PT. Rineka Cipta, Jakarta.

Peraturan Pemerintah No. 101 Than 2000 Tentang Pendidikan dan Pelatihan Jabatan PNS, Jakarta.

Recep Kacmaz and Celalettin Serinkan. Human resource management practices in internasional sebat educational school, Procedia-social and Behavioral Sciences 116 (2014) 4809-4813

Rijadi S, Strategi Pengembangan Sumberdaya Manusia Menghadapi PJPT II. Malang: FPIPS, 1994, Jurnal Ilmu Pengetahuan Social Vol, 28, Nomor 3

Sujarno, dkk, 2013, Bahan Ajar Keaksaraan Dasar, BPPAUDNI, Surabaya

Tim Direktorat Pendidikan Keaksaraan, 2010 , Pedoman Pembelajaran Pendidikan Kesetaran, Jakarta.

Yeti haeryati dan Mumuh Muhsin, 2014, Manajemen Sumberdaya Manusia, Pustaka Setia, Bandung, hal. 10-11

Yunus, Hadi Sabari, 2010. Metodologi Penelitian Wilayah Kontemporer. Pustaka Pelajar, Yogyakarta.

Thomas Sergiovanni and Martin Burlingame, 1987. Educational Govermance and Administration. New Jersey

Undang-undang Republik Indonesia nomor 20 Tahun 2003. Tentang Sistem Pendidikan Nasional

Uha Suharsaputra, 2012. Metode Penelitian

Kuantitatif, Kualitatif dan Tindakn, P. afika Aditama, Bandung

Jurnal BeduManagers, Vol.2, No.1, Juni 2021 
BEduManageRs Journal

Borneo Educational Management and Research Journal, Vol.2, No.1, 2021 ISSN: 2747-0504

Usman, Husaini, 2014. Manajemen: teori,

Aksara,Jakarta

Praktik dan riset pendidikan, Bumi 